\title{
Lexical selection and gender agreement processing
}

\author{
Masayuki Yamada, Maria do Carmo Lourenço-Gomes \\ Institute of Arts and Humanities, University of Minho, Portugal \\ https://doi.org/10.36505/ExLing-2019/10/0052/000414
}

\begin{abstract}
This study investigates the influence of lexical selection of adjectives on gender agreement in writing by late Chinese learners of European Portuguese (EP), with an online paradigm. Participants were asked to translate sentences (from Chinese to Portuguese) containing adjectives that ranged from easy to difficult, on a platform that recorded the writing process. A greater pause was observed in the difficult condition than in the easy condition at the critical position, i.e., just before the adjective. In addition, there were more errors in the difficult condition. These results suggest that when lexical selection is difficult it demands more resources from working memory (WM), and, hence, less resources are left for the agreement process, which results in more errors.
\end{abstract}

Keywords: gender agreement, lexical selection, Portuguese, Chinese

\section{Background}

Acquisition of gender agreement by late L2 learners has generated much research in the literature. There are, however, few studies on gender agreement in EP. Most have examined written corpora data and discussed the relationship between errors and noun features such as morphology and animacy (e.g., Brito, 2015; Pinto, 2014). Despite their relevant findings, their results should be interpreted with caution, because they did not distinguish between attribution errors and agreement errors in the analysis, which renders difficult to discuss the nature of the errors (whether lexical or syntactic). Furthermore, as these analyses were conducted on the final version of the texts, the online process of writing was not examined. For these reasons, Yamada et al. (2018) analysed gender agreement errors in writing by late Asian learners of EP, by using a platform developed by the author (demo: http://bit.ly/2M4FCgR), which enabled the recording and later review of how the writing process unfolded in real time due to a keystroke logging technique (for a review, see Van Waes, Leijten, Wengelin, \& Lindgren, 2011). As for noun-adjective agreement, the results suggested an independent relationship between noun's features (transparency and animacy) and occurrence of agreement errors. Moreover, an analysis of the writing process revealed that a relatively great pause was found just before the occurrence of some errors. A post-interview to the participants unveiled that they were engaged in the lexical selection of adjectives during the

ExLing 2019: Proceedings of 10 $0^{\text {th }}$ International Conference of Experimental Linguistics, 25-27 September 2019, Lisbon, Portugal 
pause, which suggests an influence of adjectives on gender marking. To our knowledge, however, the influence of adjective features on noun-adjective agreement in production has not been studied yet.

As far as agreement errors are concerned, the role of WM may be considered as well. Fayol et al. (1994) found that, when a cognitive load was imposed by a concurrent task, native French speakers made more errors of subject-verb agreement. The authors argued that the WM overloaded because of the secondary task, which made correct agreement marking difficult. McDonald (2006) reported that decreased performance of L1 speakers under cognitive load mirrors that of L2 speakers, positing that poor performance of L2 speakers resulted from a short availability of WM's resource. Based on these findings, we postulated that, if the lexical selection of adjectives was causing an overload of learners' WM and consuming its resources to a considerable extent, agreement errors were induced by it. This speculation is consistent with evidence showing that lexical process interferes with a later syntactic processing in comprehension (Hopp, 2016).

Considering the above, in the present study, we conducted a translation task (from Chinese to Portuguese) in which the difficulty of translation of adjectives was manipulated to impose cognitive load on lexical selection in order to verify whether such load induced agreement errors.

\section{Study}

Method

Forty-one native speakers of Chinese, late learners of Portuguese as a foreign language, recruited at Portuguese universities, participated in the study (Years of learning: 2.94. Mean-age: 22.6). Participants were asked to translate sentences from Chinese to Portuguese using a writing platform (the same used in Yamada et al., 2018). Target materials for the experiment consisted of six pairs of sentences with the structure: $\mathrm{NP}+\mathrm{VP}(\mathrm{V}+\mathrm{Adj} P)$, in which gender agreement between predicate adjective and the sentential subject is obligatory. Each sentence pair differed only in the adjective position. One version of the sentence contained an adjective that could be easily translated (easy condition), and the other version contained an adjective that did not translate easily (difficult condition). Adjectives were selected from a questionnaire previously conducted with 20 Chinese learners, in which adjectives were rated according to ease/difficulty of translation. An example of a sentence pair is given below (1ab):

（1） a. 葡萄牙的生活非常平静 (easy condition)

b. 葡萄牙的生活非常充实 (difficult condition)

'A vida em Portugal é muito calma [easy]/proveitosa [difficult] 'Life in Portugal is very calm / profitable.' 
A total of 24 sentences (one version of each sentence pair and 18 fillers) was assigned to two lists. Each participant received only one list.

A MacBook Pro (13-inch) with US keyboard was used. To familiarize participants with the task and all the procedures, two training sessions were implemented prior to the main experiment. On each trial each sentence in Chinese appeared at the top of the screen, and participants were asked to translate it into Portuguese in the text area and click the "next" button to access the next sentence. To control for possible fatigue, a break was inserted after half of the sentences. To confirm the appropriateness of the adjectives selected for the task, a post-questionnaire was conducted at the end of the main session, in which participants were asked to rate ease of translation of the target adjectives in a 5-point scale (from 1-very difficult to 5-very easy).

It was hypothesized that a greater pause before the adjective position and more errors (e.g., use of the default form: masculine) would occur in the difficult condition in comparison to the easy condition.

\section{Results}

As expected, a longer pause was observed in the difficult condition than in the easy condition (Mean-duration: $8738 \mathrm{~ms}$ vs. $2153 \mathrm{~ms}$ ) just before the adjective. Because of high skewness and kurtosis and some outliers, a paired t-test was performed on the log-transformed data, revealing a significant difference between the pause times of the two conditions $(t(119)=-11.767 ; p<.0001 ; d$ $=1.53)$. A Chi-square test revealed that there were significantly more errors in the difficult condition than in the easy condition $\left(\chi^{2}(1)=47.053, p<.0001, P h i=\right.$ .447). The mean score of the ease of translation for the easy and the difficult conditions was 4.85 and 2.95 points, respectively. A Wilcoxon signed-rank test revealed that this difference was significant $(Z=8.210 ; p<.0001 ; r=.74)$. A strong correlation between ease of translation and experimental condition was confirmed $(r=-.715 ; p<.0001)$.

\section{Discussion and conclusion}

The results obtained indicate that: (i) the choice of adjectives for each condition was appropriate; (ii) the difficult condition caused a cognitive load on lexical selection, leading participants to produce longer pauses at the critical position as compared to the easy condition; and (iii) a higher error rate in the difficult condition was observed. Our results seem to indicate that lexical selection may interfere with processing of agreement, which may be taken as evidence for the vulnerability of syntactic processing to processes from other cognitive levels (e.g., Badecker \& Kuminiak, 2007). We hypothesize that, as learners' agreement processing is not as automatic as that of native speakers, it may require more resources from WM; when many WM resources are required by other demanding linguistic processes, errors will occur due to the lack of resources available. 
Despite some limitations of this study (e.g., reduced number of experimental items), we have replicated experimentally a type of gender agreement error previously observed in spontaneous writing (Yamada et al., 2018). We believe our findings may contribute to the L2 teaching/learning field and to the development of theoretical models of writing.

\section{Notes}

\section{This study is part of the first author's ongoing $\mathrm{PhD}$ thesis.}

\section{References}

Badecker, W., Kuminiak, F. 2007. Morphology, agreement and working memory retrieval in sentence production: Evidence from gender and case in Slovak. Journal of Memory and Language, 56(1), 65-85.

Brito, E. 2015. Grammatical gender in the interlanguage of English-speaking learners of Portuguese. Portuguese Language Journal, 9, 1-21.

Fayol, M., Largy, P., Lemaire, P. 1994. When cognitive overload enhances subject-verb agreement errors. The Quarterly Journal of Experimental Psychology Section A, 47(2), 437-464.

Hopp, H. 2016. The timing of lexical and syntactic processes in L2 sentence comprehension. Applied Linguistics, 37(5), 1253-1280.

McDonald, J.L. 2006. Beyond the critical period: Processing-based explanations for poor grammaticality judgment performance by late second language learners. Journal of Memory and Language, 55(3), 381-401.

Pinto, J. 2014. A aquisição do género e da concordância de género em português língua terceira ou língua adicional. In P. Osório \& F. Bertinetti, Teorias e Usos Linguísticos. Lisboa: Lidel.

Van Waes, L., Leijten, M., Wengelin, Å., Lindgren, E. 2011. Logging tools to study digital writing processes. In V. W. Berninger (Ed.), Past, Present, and Future Contributions of Cognitive Writing Research to Cognitive Psychology. Psychology Press.

Yamada, M., Lourenço-Gomes, M. do C., Barbosa, P. 2018. Uma análise de tempo real da concordância de género na produção escrita por aprendentes de PLE. Presented at the XXXIV ENAPL 2018, Lisboa, Universidade Aberta. 